\title{
The Role of Ethylene in Plants Under Salinity Stress
}

\author{
Jian-Jun Tao, Hao-Wei Chen, Biao Ma, Wan-Ke Zhang, Shou-Yi Chen and Jin-Song Zhang* \\ State Key Lab of Plant Genomics, Institute of Genetics and Developmental Biology, Chinese Academy of Sciences, Beijing, \\ China
}

Although the roles of ethylene in plant response to salinity and other stresses have been extensively studied, there are still some obscure points left to be clarified. Generally, in Arabidopsis and many other terrestrial plants, ethylene signaling is indispensable for plant rapid response and tolerance to salinity stress. However, a few studies showed that functional knock-out of some ACSs increased plant salinity-tolerance, while overexpression of them caused more sensitivity. This seems to be contradictory to the known opinion that ethylene plays positive roles in salinity response. Differently, ethylene in rice may play negative roles in regulating seedling tolerance to salinity. The main positive ethylene signaling components MHZ7/OsEIN2, MHZ6/OsEIL1, and OsEIL2 all negatively regulate the salinity-tolerance of rice seedlings. Recently, several different research groups all proposed a negative feedback mechanism of coordinating plant growth and ethylene response, in which several ethylene-inducible proteins (including NtTCTP, NEIP2 in tobacco, AtSAUR76/77/78, and AtARGOS) act as inhibitors of ethylene response but activators of plant growth. Therefore, in addition to a summary of the general roles of ethylene biosynthesis and signaling in salinity response, this review mainly focused on discussing (i) the discrepancies between ethylene biosynthesis and signaling in salinity response, (ii) the divergence between rice and Arabidopsis in regulation of salinity response by ethylene, and (iii) the possible negative feedback mechanism of coordinating plant growth and salinity response by ethylene.

Keywords: ethylene, salinity stress, MHZ, NtTCTP, negative feedback

\section{INTRODUCTION}

Salinity has extensive negative effects on plant growth, including ion toxicity, osmotic stress, oxidative stress, and nutrient deficiency (Chinnusamy et al., 2006; Zhu, 2007). These hazards lead to growth inhibitory, crop yield reduction, and even death under prolonged high salinity condition. For improper irrigation and drainage, back flow of seawater, abuse of chemical fertilizer, and some other reasons, more and more arable land tends to be threatened by salinity. Salinity will usually lead to soil sodicity and alkalinity. Therefore, salinity stress has turned out to be one of the major factors limiting the sustainable development of agriculture. For a long time, people have focused on elucidating the physiological effects of salinity stress on plants, dissecting genetic components responsible for salinity stress response and resistance, and improving plant tolerance to salinity mainly through hybridization and gene transformation. Nowadays, studies at integrative levels become prevalent to uncover the intrinsic mechanism for plant rapid responses and self-modulation of vegetative and reproductive growth to adapt to salinity condition. 
Throughout the life cycles of plants, phytohormones play vital roles in controlling the interaction between plants and environments, including plant responses to salinity stress. One of the phytohormones involved in salinity response is ethylene, which is also regarded as a stress-hormone besides its roles in regulation of plant growth and development (Abeles et al., 1992). Levels of ethylene and its direct precursor ACC could be obviously induced by salinity and other abiotic stresses in many plant species (Morgan and Drew, 1997). Compared to the glycophyte Arabidopsis thaliana, two halophytes Cakile maritima and Thellungiella salsuginea accumulated more ACC in both leaves and roots under high salinity (Ellouzi et al., 2014). In soybean, a research using 2-DE gel analysis found that several components of ethylene biosynthesis in the salt-tolerant genotype Lee 68 were more abundant than that in the saltsensitive genotype Jackson under salinity stress (Ma et al., 2012). Application of ethylene or ACC could improve plant tolerance to high salinity (Cao et al., 2007), largely through enhancing the expression of reactive oxygen species (ROS) scavengers (Peng et al., 2014a). Further studies based on gene mutation and transformation analysis elucidated that the whole ethylene biosynthesis and signal transduction pathway are involved in plant response and adaptation to salinity. Generally, promotion of ethylene biosynthesis and signal transduction could enhance plant tolerance to salinity, while inhibition of it leads to increased plant sensitivity to salinity.

However, some other works showed that ACC may play a negative role in regulation of tomato seedling growth under salinity (Albacete et al., 2009). In tomato, ACC in leaves was increased prior to $\mathrm{Na}^{+}$accumulation, and was coincident with the onset of oxidative stress and leaf senescence under salinity stress (Ghanem et al., 2008). Although these results did not show the direct effects of ACC on plant response to salinity, and some other works revealed that ethylene is not the primary factor in salinity-induced plant growth inhibition (Shibli et al., 2007), it is still possible that ethylene may play a subtle negative role in plant response to salinity, at least at a certain growth stage. A further discussion is therefore necessary for us to understand the actual roles of ethylene in plant response to salinity.

In this review, we summarized and discussed roles of the whole ethylene biosynthesis and signaling pathway in plant response to salinity stress. The interactions between ethylene and ABA, jasmonic acid (JA) and some other signaling molecules, and the cross-talks between plant response to salinity and response to nutrient deficiencies were also compared. Some possible divergent roles of ethylene in different plant species were discussed as well.

\section{ETHYLENE BIOSYNTHESIS AND SALINITY STRESS}

Ethylene is a simple gaseous hormone which plays multiple roles in regulation of plant growth and development, and also serves as a key modulator between plant response to environmental stresses and normal growth (Abeles et al., 1992). Under salinity and some other stresses, ethylene production is quickly stimulated (Morgan and Drew, 1997). In fact, several key steps of ethylene biosynthesis could be affected by salinity and other stresses. Ethylene in plant is synthesized through three enzymatic reaction steps: methionine is converted to $S$-adenosyl-methionine ( $S$-AdoMet) by $S$-AdoMet synthetase; then the direct precursor of ethylene ACC is synthesized from S-AdoMet by ACS (ACC synthase); and finally ethylene is produced through the oxidation of ACC by ACO (ACC oxidase) (reviewed in Lin et al., 2009). S-AdoMet is also the precursor for the synthesis of polyamines, which also plays a role in plant response to biotic and abiotic stresses. The by-product MTA ( $5^{\prime}$-methylthioadenosine) from the second step is recycled to methionine through the Yang Cycle to maintain a stable methionine pool even when ethylene is rapidly synthesized (Yang and Hoffman, 1984; Kende, 1993).

As a rate-limiting enzyme, ACS is the major target for regulation of ethylene production under stresses (Yang and Hoffman, 1984; Kende, 1993; Bleecker and Kende, 2000; Wang et al., 2002). There are eight functional ACS genes in Arabidopsis. They have redundant role in ACC biosynthesis (Tsuchisaka and Theologis, 2004; Tsuchisaka et al., 2009), while each with unique function in the regulation of plant growth and development. The regulation of ACSs under stress occurs at both transcriptional and post transcriptional levels. Under salinity, transcripts of ACS2 and ACS7 in Arabidopsis were increased dramatically (Achard et al., 2006). Through GUS staining, Arabidopsis ACS5 and ACS7 promoters were found to be induced by salinity (Wang et al., 2005). A more systematic research revealed that the MAPK cascade-induced by stress might activate WRKY33 which then promoted the expression of ACS2/ACS6 genes in Arabidopsis ( $\mathrm{Li}$ et al., 2012). In tobacco, the transcripts of ACS1 were induced by salinity (Cao et al., 2006). In cotton, a series of ACSs were up-regulated under both short- and long-time salinity condition (Peng et al., 2014b). Recent work in Arabidopsis found that four ACSs (ACS2, ACS6, ACS7, and ACS8) were induced by high salinity, while a moderate low salinity pretreatment (known as salt acclimation) alleviated this induction (Shen et al., 2014). This result provides us a cue that promotion of ethylene production by a strong and sudden salinity stress might have multiple effects for plant response to salinity. It seems that no extra ethylene was needed for the process of salt acclimation, because there were no changes on the expression of genes related to ethylene biosynthesis (Shen et al., 2014). Four ACSs were up-regulated no matter under NASS (non-acclimated salt stress) or SASS (salt acclimated salt stress; Shen et al., 2014), indicating that promotion of ethylene production is still necessary for plant adaption to the stress condition. Nevertheless, transcripts of ACSs under SASS were less than those under NASS (Shen et al., 2014). These results suggest that a tight control of ethylene biosynthesis might be important for plant response and adaption to salinity stress.

Besides transcriptional regulation, some ACSs are also regulated post-transcriptionally under salinity, mainly through stress-activated MAPK (mitogen-activated protein kinase) cascades which phosphorylate ACSs protein and then prevent them from $26 \mathrm{~S}$ proteasome-mediated degradation. Under biotic and abiotic stresses, Arabidopsis MPK6 was activated rapidly to phosphorylate ACS2 and ACS6 to elevate ethylene production (Liu and Zhang, 2004). In tomato, it was shown that calciumdependent protein kinases (CDPKs)-mediated phosphorylation stabilized ACS2, leading to increased ACC content in stressed 
tissues (Tatsuki and Mori, 2001; Kamiyoshihara et al., 2010). In Arabidopsis, loss-of-function of MPK6 diminished the effects of salt acclimation, leading to more sensitivity to high salinity (Shen et al., 2014).

Another key ethylene biosynthesis enzyme ACO is also regulated by salinity. Under high salinity, both ACC content and ACO activity were increased to enhance ethylene release in Cicer arietinum root (Kukreja et al., 2005). In cotton, several ACOs were up-regulated under both short- and long-time salt treatment (Peng et al., 2014b). From these results, we can propose that plants under salinity and other abiotic and biotic stresses tend to produce more ethylene mainly through enhancing ACSs and ACOs. Nevertheless, transcripts of ACO1 in wheat were decreased under salinity and other abiotic stresses (Chen et al., 2014).

Although ACSs and ACOs are usually up-regulated under salinity, these key enzymes for ethylene biosynthesis may play negative roles in plant salinity-response. In Arabidopsis, loss-offunction of ACS7 conferred less ethylene emission, promoted vegetative growth and enhanced tolerance to salinity (Dong et al., 2011). Constitutive expression of wheat ACO1 in Arabidopsis led to salinity-sensitivity, possibly through increasing the expression of AtMYB15 while suppressing some stress-responsive genes like AtRAB18, AtCBF1, and AtCBF3 (Chen et al., 2014). Expression of MKK9 in transgenic plants activated the endogenous MPK3 and MPK6 kinases, promoted the synthesis of ethylene and camalexin, and finally conferred increased sensitivity to salinity, whereas loss-of-function mutant $m k k 9$ showed enhanced tolerance to salinity (Xu et al., 2008). Recent work in rice found that a lectin receptor-like kinase SIT1 (salt intolerance 1) mediated salinity sensitivity through regulation of ethylene homeostasis (Li et al., 2014a). In presence of salinity stress, SIT1 was activated rapidly to phosphorylate MPK3/6 and then promote ethylene production ( $\mathrm{Li}$ et al., 2014a). Overexpression of SIT1 in rice and Arabidopsis both conferred increased sensitivity to salinity, while loss-of-function of MPK3/6 alleviated this effect (Li et al., 2014a). Expression of SIT1 in rice and Arabidopsis also enhanced the ROS accumulation in an MPK3/6- and ethylene signaling-dependent manner ( $\mathrm{Li}$ et al., 2014a). All indicate a SIT1-MPK3/6 cascade mediates salt sensitivity by regulating ethylene homeostasis. In addition, plant growth-promoting rhizobacteria (PGPR) produced AcdS (ACC deaminase), which facilitated the growth and stress tolerance of hosts via a reduction in levels of ethylene (Ali et al., 2014; Barnawal et al., 2014; Kim et al., 2014). Transgenic Arabidopsis expressing AcdS showed reduced sensitivity to exogenous ACC but increased tolerance to high salinity. In contrast, AcdSsilenced Trichoderma mutants were less effective in promoting plant tolerance to salinity, indicating that Trichoderma can also ameliorated plant growth under salinity stress by decreasing the ethylene biosynthesis in hosts (Brotman et al., 2013).

In contrast to the studies above, some other works showed that ethylene biosynthesis has positive effects on salinity-response. As stated above, MPK6, a key regulator of ethylene biosynthesis under stresses, was necessary for salt acclimation (Shen et al., 2014). That means plants may need MPK6 to stabilize ACSs and maintain a relative high ethylene level to accomplish the salt acclimation. The BTB ubiquitin ligases ETO1, EOL1, and EOL2 could interact with ACS5, promoted its ubiquitination and then accelerated its degradation (Christians et al., 2009). The expression of ETOL1 in rice was induced under $200 \mathrm{mM}$ $\mathrm{NaCl}$ treatment (Du et al., 2014). In Arabidopsis, loss-of-function of ETO1 increased ethylene production and improved seedling tolerance to soil-salinity. Lack of ETO1 reduced root $\mathrm{Na}^{+}$ influx and so restricted root-to-shoot delivery of $\mathrm{Na}^{+}$, and these effects were associated with increased RBOHF-dependent ROS accumulation in root stele. In addition, loss-of-function of ETO1 enhanced the tissue $\mathrm{K}^{+}$status through an RBOHFindependent manner associated with increased transcripts of the $\mathrm{K}^{+}$-transporter HAK5 (Jiang et al., 2013).

From these results, a definitive conclusion could not be drawn as to whether ethylene biosynthesis plays positive or negative roles in plant response to salinity. The discrepancy in the role of ethylene biosynthesis in salt response may be due to that, usually a single member of genes in the ethylene biosynthesis pathway, but not the whole status, was evaluated. And the optimal ethylene level for normal plant growth may be varied at different stages and in different plant species. From an evolutionary perspective, the induction of ethylene under stress condition should have some advantages for plant survival. In fact, pretreatment with ACC enhanced the salinity-tolerance of Arabidopsis seedlings (Peng et al., 2014a). We propose that ethylene indeed plays a positive role in the early stage of plant self-adjustment or salt acclimation for better survival under high salinity stress. After the stage of self-adjustment, excessive ethylene in plants will inhibit plant growth and development, which is disadvantageous for plants to survive under high salinity stress. Additionally, various ethylene receptors, whose functions are negatively regulated by ethylene, may also "neutralize" the ethylene role in salt stress. A homeostasis between ethylene and its receptors may facilitate plant survival under salinity stress.

There are multiple ACSs and ACOs members with functional redundancy on ethylene synthesis. Single mutation of one member only decreased ethylene emission in a limited level, and this may have little effect on salt acclimation. However, under high salinity, single mutation of ACS or ACO might decrease the induction of ethylene and alleviate excessive ethylene-induced growth inhibition, and hence keep higher growth potential for plants. Another possible reason is the competition for $S$ AdoMet as the precursor between ethylene and PA (polyamines) biosynthesis. Decreasing the ACS and ACO activity in tobacco could promote the biosynthesis of $\mathrm{PA}$, and so enhance plant tolerance to abiotic stresses including high salinity through PAmediated pathway (Wi and Park, 2002). Additionally, ACC itself might act as a signaling molecule in plants (reviewed in Yoon and Kieber, 2013), and so possibly mediates some unknown salinity response pathways. Further research based on analysis of multiple mutants of ACSs or treatments with different ethylene biosynthesis inhibitors will shine a light on the mechanisms involved.

\section{ETHYLENE SIGNALING AND SALINITY STRESS}

Based on the classical "triple response" (inhibited hypocotyl and root elongation, enhanced horizontal growth and exaggerated 
apical hook of etiolated seedlings), a series of ethylene response mutants were characterized in Arabidopsis. The ethylene signal transduction model was then established through genetic and biochemical analysis of these mutants. Main components of this model include five ethylene receptors, a negative regulator CTR1, a key positive regulator EIN2, primary transcription factors EIN3/EILs and many downstream ethylene-response factors. In normal condition, ethylene receptors interact with and activate CTR1, which then phosphorylates EIN2 and prevents its translocation into nucleus, therefore inhibits ethylene signal transduction. When developmental or environmental signals induce ethylene production, ethylene binds with receptors to inhibit their interaction with CTR1, and CTR1 is inactivated, leading to the dephosphorylation and cleavage of EIN2. Then the C-terminus of truncated EIN2 is translocated into nucleus to stabilize downstream transcription factors EIN3/EILs (Ju et al., 2012; Qiao et al., 2012; Wen et al., 2012). Finally, transcriptions of downstream ethylene response factors are activated by EIN3/EIL1 and lead to extensive ethylene responses. In this pathway, EIN2 is regulated by ETP1/ETP2 mediated protein turnover (Qiao et al., 2009) and EIN3 is regulated by EBF1/EBF2-dependent ubiquitination and degradation (Guo and Ecker, 2003; Potuschak et al., 2003; Gagne et al., 2004; Binder et al., 2007; An et al., 2010). Ethylene receptors are also regulated by proteasome-mediated protein degradation (Chen et al., 2007; Kevany et al., 2007; Shakeel et al., 2015; Tao et al., 2015). More recently, two groups reported new advances of ethylene signaling. Li et al. (2015a) found that ethylene induced EIN2 to associate with the $3^{\prime}$-UTR of EBF1/2 mRNA and target $E B F 1 / 2$ mRNA to the cytoplasmic processingbody (P-body) through interaction with multiple P-body factors, leading to the stabilization of EIN3/EIL1 and activation of downstream events. Merchante et al. (2015) adopted genomewide ribosomal footprinting and RNA-seq methods to identify translationally-regulated genes by ethylene, and they found that EIN2 and non-sense-mediated decay proteins UPFs are required for the translational regulation of EBF1/2.

As a stress hormone, the whole signaling pathway of ethylene is involved in plant response to salinity stress and possibly mediated the stress signal transduction. First, the expressions of many ethylene signaling genes are regulated by salinity and other stresses. In Arabidopsis, the expression of ETR1 was suppressed by osmotic stress including salinity (Zhao and Schaller, 2004). In tobacco, the mRNA quantity of ethylene receptor NTHK1 was dramatically increased under salinity stress (Zhang et al., 2001; Cao et al., 2006, 2007; Zhou et al., 2006). Further research discovered that NTHK1 was regulated by proteasome-mediated degradation, while its interaction with NtTCTP could stabilize itself (Tao et al., 2015). In cotton, several ethylene receptor genes (ETR1, ETR2, and EIN4), ethylene signaling genes (CTR1, EIN3, ERF1, and ERF2) and MAPK cascade genes (MEKK1-MKK2$M P K 4 / 6)$ were all up-regulated under both short- and longtime salt treatments (Peng et al., 2014b). Besides, salt treatment promoted the degradation of EBF1/EBF2 and so enhanced the EIN3 protein accumulation in an EIN2-independent manner (Peng et al., 2014a). Additionally, salinity also promoted the transcriptional activity of EIN3 in an EIN2-dependent manner (Peng et al., 2014a).
Second, based on mutation and transgenic analysis, almost all ethylene signaling components were found to participate in plant response to salinity and other stresses. In Arabidopsis, etr1 loss-of-function mutants showed enhanced tolerance to high salinity, whereas gain-of-function mutant etr1-1 displayed increased sensitivity to salt stress (Zhou et al., 2006; Cao et al., 2007; Peng et al., 2014a). Overexpression of NTHK1 in tobacco and Arabidopsis led to reduced sensitivity to ethylene but enhanced sensitivity to salinity (Cao et al., 2006). Addition of ACC to the treatment alleviated the salinity sensitivity caused by the overexpression of NTHK1 in Arabidopsis, but has no effects on the gain-of-function mutants of ethylene receptors (etr1-1 and ein4-1, Cao et al., 2007). Further truncation and mutation analysis of NTHK1 showed that the transmembrane domain, the kinase domain and the kinase activity were indispensable for its roles in conferring reduced sensitivity to ethylene but enhanced sensitivity to salinity (Zhou et al., 2006; Chen et al., 2009). Besides redundant roles in ethylene perception, each ethylene receptor has some specific roles (reviewed in Shakeel et al., 2013). The specificity of ethylene receptors was reflected partly in their roles in salinity response. In Arabidopsis, ETR1 and ETR2 had contrasting roles in seed germination during salt stress, which seems to be mediated by affecting the ABA signaling but independent of ethylene signaling (Wilson et al., 2014). Tobacco subfamily II receptor NTHK1 played stronger roles than the subfamily I receptor ETR1 in regulation of seedling growth and salinity response (Chen et al., 2009). By yeast two-hybrid screening, an ankyrin domain-containing protein NEIP2 was identified to interact with NTHK1 and mediated plant response to salinity stress (Cao et al., 2015).

Besides the receptors, downstream ethylene signaling components also participated in salinity response. Loss-offunction of the key negative ethylene signaling factor CTR1 led to more tolerance to salinity stress (Achard et al., 2006; Peng et al., 2014a), possibly through modulation of shoot $\mathrm{Na}^{+}$ and $\mathrm{K}^{+}$homeostasis which was dependent on ETR1-CTR1regulated ethylene signaling (Jiang et al., 2013). The key positive ethylene signaling factor downstream of CTR1 is EIN2, which is found to confer salinity tolerance. Arabidopsis seedlings with loss-of-function of EIN2 became more sensitive to salinity, while overexpression of the C-terminus of EIN2 in ein2-5 suppressed the salinity sensitivity (Cao et al., 2007; Lei et al., 2011a; Peng et al., 2014a). By yeast two-hybrid screening, a MA3 domain-containing protein ECIP1 was identified to interact with EIN2. Loss-of-function of ECIP1 led to minor enhanced ethylene response and salt tolerance during seedling growth but conferred salt sensitivity during seed germination process (Lei et al., 2011a). EIN3/EILs are the primary transcription factors for ethylene signal transduction from EIN2 to nuclear transcriptional regulation. In Arabidopsis, loss-of-function mutant ein3-1 and the double mutant ein3eil1 exhibited severe sensitivity to salinity, whereas overexpression of EIN3 enhanced seedling tolerance to salinity (Achard et al., 2006; Lei et al., 2011a; Peng et al., 2014a). Single mutant ebf1-1 and double mutant ebf1-1ebf2-1 also showed enhanced tolerance to salinity in an EIN3-dependent manner (Achard et al., 2006; Peng et al., 2014a). 
Generally, in plant response to salinity, positive components of ethylene signaling are up-regulated by salinity and play positive roles, whereas negative factors are correspondingly down-regulated and play negative roles. In one word, ethylene signaling is necessary for plant response and adaption to salinity stress. However, ethylene response and signaling in rice, a semi-aquatic plant, seems to be somewhat different from Arabidopsis (Yang et al., 2015a). Based on the ethylene "double response" (promotes coleoptile growth but inhibits root elongation of dark-grown etiolated seedlings) in rice, a series of ethylene-response mutants $m h z$ (maohuzi) were identified (Ma et al., 2010, 2013). These mutants were insensitive to ethylene on root elongation but showed differential responses on coleoptile growth. Unexpectedly, but interestingly, except for MHZ7 (a homolog of EIN2) and MHZ6 (a homolog of EIN3), other MHZs were either novel components with no homologies to ethylene signaling pathway proteins in Arabidopsis or cross-talk points interacting with other hormones (Ma et al., 2013), indicating a special feature for ethylene signaling pathway in rice. Both MHZ4 and MHZ5 were involved in ABA biosynthesis, and mediated ethylene-controlled root growth (Ma et al., 2014; Yin et al., 2015). MHZ6/OsEIL1 and OsEIL2 respectively regulated ethylene-controlled root and coleoptile growth of etiolated seedlings. Unlike the positive roles of EIN2 and EIN3 in salinity response in Arabidopsis, MHZ7/OsEIN2, MHZ6/OSEIL1, and OsEIL2 exhibited the opposite effects on the salinity tolerance of rice seedlings. Functional knock-out of MHZ7/OsEIN2, MHZ6/OSEIL1, or OsEIL2 led to enhanced salt tolerance, while overexpressing each of them increased seedling sensitivity to salinity (Yang et al., 2015b). $\mathrm{Na}^{+}$measurement and downstream gene analysis revealed that MHZ6/OSEIL1 and OsEIL2-regulated salinity responses were mediated through controlling the expression of OsHKT2; $1, \mathrm{a} \mathrm{Na}^{+}$transporter gene, and the homeostasis of $\mathrm{Na}^{+}$in plants (Yang et al., 2015b). EMSA and luciferase assay showed that both MHZ6/OSEIL1 and OsEIL2 could bind to the promoter region of OsHKT2;1 and promoted its transcription (Yang et al., 2015b). Particularly, there is no homolog of OsHKT2;1 in Arabidopsis, indicating that OsHKT2;1 may be the major reason of difference between rice and Arabidopsis on the role of ethylene in salinity response. It is likely that rice adopts the ethylene signaling pathway to activate OsHKT2;1 expression and $\mathrm{Na}^{+}$uptake for cell ion homeostasis in water-saturated soil. However, this mechanism would lead to the excessive $\mathrm{Na}^{+}$uptake under high salinity condition and result in the salt sensitivity. Further studies on the roles of other rice ethylene signaling components in salinity response would generate more valuable data for elucidating the differences between terrestrial plants and aquatic/semi-aquatic plants on salinity response.

\section{DOWNSTREAM EVENTS IN ETHYLENE MEDIATED SALINITY RESPONSE}

The main ethylene signaling components downstream of EIN3 are ERFs (ethylene-responsive element binding factors), which are plant-specific transcription factors responsible for nuclear transcriptional regulation of a series of effectors related to ethylene response. In Arabidopsis, the three classes of ERFs, with either transcriptional-activation or -repression activities, were differentially regulated by ethylene and abiotic stresses (Fujimoto et al., 2000). EIN3/EILs could bind directly to the promoter of ERF1 and activate its expression. Similar to EIN3-overexpression in transgenic plants, expression of ERF1 also activated a variety of ethylene response genes and led to constitutive ethylene response (Solano et al., 1998). The expressions of AtERF1, AtERF2 and AtERF5 were all induced by ethylene treatment in an EIN2dependent manner. The induction of AtERF3 and AtERF4 by high salinity stress was regulated by EIN2-mediated ethylene signaling (Fujimoto et al., 2000). Further analysis showed that $E R F 1$ was highly induced by salinity and drought stress in an ethylene and JA signaling-dependent manner. Overexpression of ERF1 enhanced plant tolerance to salt, drought and heat stress (Cheng et al., 2013). Although overexpression of many ERFs genes could enhance salt tolerance, most of them seem to be independent of ethylene signaling. Based on microarray analysis, three ERFs genes in Arabidopsis, named as ESE1 to $E S E 3$, were found to be ethylene- and salt-inducible. Among them, ESE1 was positively regulated by ethylene signaling at transcriptional level, and was downstream of EIN3/EIL1. Further analysis revealed that EIN3 could physically bind to the promoter of ESE1 and activate its transcription. Then, ESE1 bound to the promoters of RD29A, COR15A and some other salinity-responsive genes to promote their transcription, and eventually enhanced plant tolerance to salinity (Zhang et al., 2011b).

Besides ERFs, some other factors were also found to be responsive to ethylene signaling and involved in salinity response. A NAC-type transcription factor gene AtNAC2 was induced by ACC, ABA, NAA, and salinity treatments. The salt induction of AtNAC2 was enhanced in ethylene-overproducing mutant eto1-1, but repressed in ethylene-insensitive mutants etr1-1 and ein 2-1, and auxin-insensitive mutant tir1-1. Overexpression of AtNAC2 promoted lateral root development under both normal and salinity conditions (He et al., 2005). In Arabidopsis, NEK6, a NIMA-related kinases (NEKs), was induced by ACC and salinity. NEK6 positively regulated plant growth, seed yield and plant response to salinity and osmotic stresses, probably through suppression of ethylene biosynthesis and activation of cell division (Zhang et al., 2011a). In addition, many other stressresponsive factors, such as TINY (a GCC/DRE-binding proteinlike transcription factor; Sun et al., 2008), AtMYB15 (a negative regulator of $\mathrm{DREB} 1 / \mathrm{CBF}$ ), $\mathrm{RAB} 18$ (an $\mathrm{ABA}$ responsive factor; Chen et al., 2014), and SIED1 (salt-induced and EIN3/EIL1dependent 1; Peng et al., 2014a), were also found to be regulated by ethylene signaling and mediate ethylene-involved salinity responses.

Through these factors, ethylene-mediated salinity signaling was transferred into a series of nuclear transcriptional cascades which led to the expression changes of numerous stress-related effectors. Generally, these effectors could be classified into three major types according to their bio-functions in stress responses: (1) ROS scavengers such as SOD and POD (Kukreja et al., 2005; Peng et al., 2014a); (2) ion transporters such as HAK5 and HKTs (Moller et al., 2009; Jiang et al., 2013; Yang et al., 2015b); (3) osmolyte synthetic enzymes such as P5CS (Hsieh et al., 2013). Changes of 
these effectors usually led to physiological modification (such as homeostasis of ROS and $\mathrm{Na}^{+} / \mathrm{K}^{+}$) of plants for better adaptation to salinity condition.

\section{INTERACTIONS BETWEEN ETHYLENE AND OTHER SIGNALS UNDER SALINITY}

In addition to directly regulating salinity-related effectors, ethylene also coordinates with some other phytohormones and stress signaling molecules to modulate plant response to salinity and normal growth. As an essential stress hormone, ABA participates in plant response to a series of biotic and abiotic stresses. Interactions between ABA and ethylene signaling in seed germination are extensively investigated. Ethylene ETR1-CTR1EIN2 signaling suppressed ABA signaling in seeds, thus alleviated ABA-mediated inhibition of seed germination (Beaudoin et al., 2000). And NO was proposed to be an interactor between ethylene and ABA in seed (reviewed in Arc et al., 2013). The relationship between ethylene and $\mathrm{ABA}$ in salinity response is not as clear as in seed germination. Nevertheless, from ABA-associated expression pattern and mutant phenotypes of ethylene-related factors, we proposed that the whole ethylene biosynthesis and signal transduction pathway interacted with $\mathrm{ABA}$ in regulating salinity response. The expressions of AtACS5, AtACS7, TaACO1, OsERF3, GmERF3, GhERF1, and some other ethylene-related genes (Wang et al., 2005; Qiao et al., 2008; Zhang et al., 2009, 2013; Chen et al., 2014) were all regulated by ABA and salinity. Mutation of ACS7 enhanced plant tolerance to salt, osmotic and heat stresses, possibly through elevating the expression of stressresponsive genes involved in $\mathrm{ABA}$ signaling under salinity (Dong et al., 2011). In Arabidopsis, etr1 loss-of-function mutants showed reduced sensitivity to $A B A$ and accelerated seed germination, while etr 2 loss-of-function mutants became more sensitive to $\mathrm{ABA}$ and germinated slower than the wild type, indicating contrasting roles of ETR1 and ETR2 in seed germination during salt stress. But this seemed to be mediated by affecting the ABA signaling but independent of ethylene signaling (Wilson et al., 2014). Disruption of EIN2 increased ABA level but substantially reduced the induction of $R D 29 B$ under high salinity (Wang et al., 2007). Actually, the central ethylene signaling component EIN2 plays an important role in mediating the interactions between ethylene and several other hormones, including ABA.

In rice, MHZ4 (homologous to Arabidopsis ABA4) and MHZ5 (carotenoid isomerase), identified from $m h z$ ethylene-response mutants, are involved in ABA biosynthesis (Ma et al., 2014; Yin et al., 2015). Mutation of either MHZ4 or MHZ5 reduced the ABA level but promoted ethylene production in etiolated seedlings. Ethylene treatment induced the expressions of $M H Z 4$ and MHZ5, thus increased the accumulation of ABA in roots. Loss-of-function mutants of MHZ4 and MHZ5 showed alleviated ethylene-inhibition of root growth, and this could be largely rescued by $A B A$ treatment. Genetic analysis revealed that both MHZ4 and MHZ5-dependent ABA pathways acted downstream of ethylene receptors to positively regulate root response to ethylene (Ma et al., 2014; Yin et al., 2015). These findings first uncovered a different mechanism of controlling root growth in rice by ethylene-ABA interaction, while in Arabidopsis ABA is not necessary for ethylene to inhibit root growth. Given that ABA production and signaling are necessary for plant responses to salinity and other stresses, MHZ4 and MHZ5 are anticipated to have some roles in plant responses to salinity and other stresses. Thus, besides regulating seedling growth, MHZ4 and MHZ5 may also mediate the interaction between ethylene and ABA on controlling stress responses.

In addition, some other stress-related phytohormones are also related to ethylene in salinity response, including JA, SA (salicylic acid), BR (brassinosteroid), and so on. It was reported that the cross-effects between ethylene, JA, SA, and $\mathrm{BR}$ signaling pathways played important roles in plant defense response (Divi et al., 2010; Yang et al., 2013). They may function synergistically or antagonistically to precisely regulate defense responses. Loss-of-function of EIN2 eliminated plant response to JA, and expression of the EIN2-CEND was sufficient to recover this responsiveness, indicating that EIN2 is a molecular link between ethylene and JA signaling pathway (Alonso et al., 1999). It was shown that EIN3/EIL1-ERF1 might act as a node to integrate JA and ethylene signaling and regulate plant development as well as stress defense (Lorenzo et al., 2003; Zhu et al., 2011). In Arabidopsis, ERF1 played positive roles in plant tolerance to salinity, drought and heat stress by regulation of stress-related genes, which integrated the ethylene, JA and ABA signals (Cheng et al., 2013). In rice, the ethylene, JA and SA pathways are all involved in the induction of OsPR10 by stress, and OsERF1 may function in both ethylene and JA pathway to regulate this induction (Takeuchi et al., 2011). Ethylene insensitive mutant ein 2 exhibited hypersensitivity to salinity on seed germination. This hypersensitivity could be rescued by treatment with 24-epibrassinolide (EBR; Divi et al., 2010). Besides these stress-hormones, ethylene also interacts with auxin extensively on regulation of plant growth and development (reviewed in Vandenbussche et al., 2012). Recently, several auxin-related small proteins (SAURs and ARGOS) from Arabidopsis were found to act as brakes of ethylene signaling and as accelerators of cell proliferation and/or cell expansion to coordinate seedling growth and ethylene response (Li et al., 2015b; Rai et al., 2015). We propose that these proteins may also act as modulators in regulation of plant growth under salinity and other stresses.

Moreover, on regulation of salinity response, ethylene also interacts with many stress signaling molecules, including ROS and cGMP. In rice, salinity triggered MAPK cascades to stabilize ACSs, led to enhanced ethylene production and ethylene signaling, which then promoted ROS accumulation and growth inhibition (Li et al., 2014a; reviewed in Steffens, 2014). In Arabidopsis, salinity-induced EIN3/EIL1 conferred enhanced tolerance to salinity by promoting the ROS scavenging in an EIN2-independent manner (Peng et al., 2014a). Both ACC and cGMP treatments could promote the ethylene production and alleviate salinity-induced injury by homeostasis of $\mathrm{Na}^{+} / \mathrm{K}^{+}$. Further analysis based on the ethylene-insensitive mutant etr1-3 and treatments with ethylene biosynthesis inhibitor and guanylate cyclase inhibitor revealed that cGMP modulated ethylenemediated salinity response pathway by regulation of ethylene biosynthesis and perception (Li et al., 2014b). 


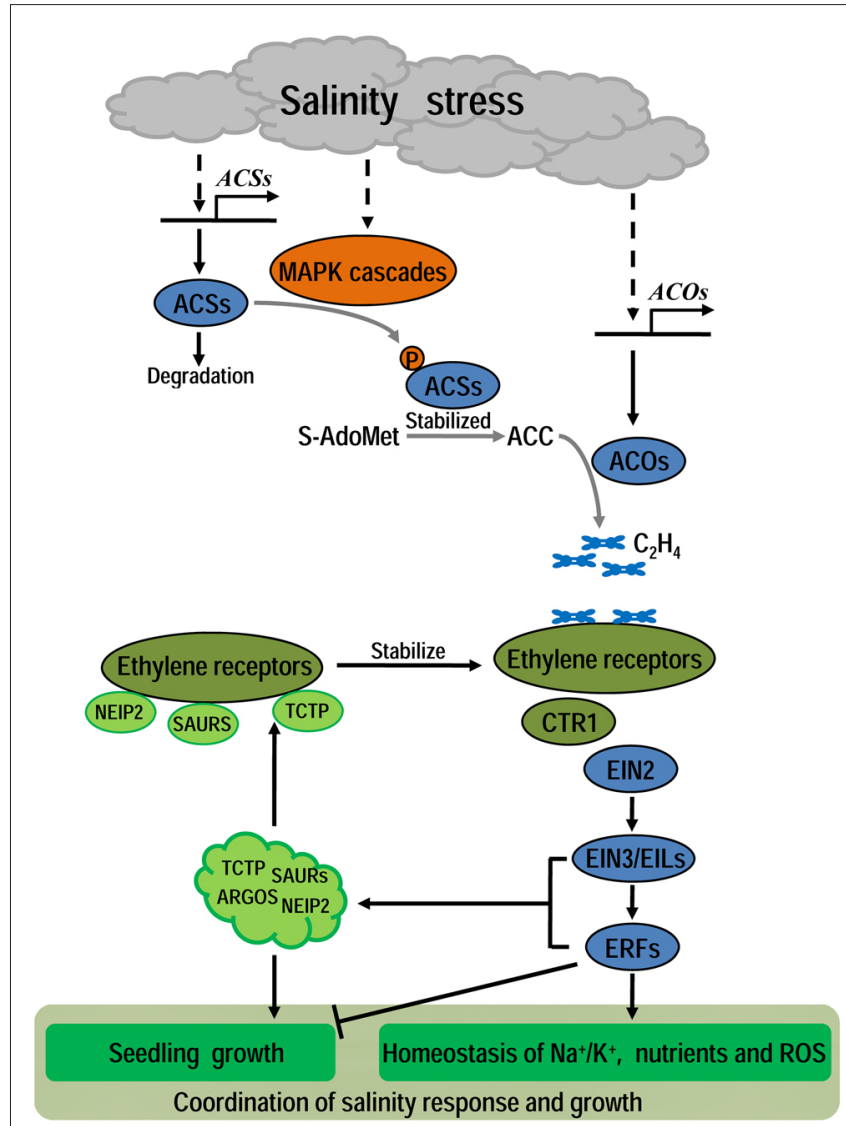

FIGURE 1 | A diagram of the ethylene's role in plant under salinity. Under salinity, stress signals could activate the MAPK phosphorylation cascades which then stabilize some ACSs to promote ethylene production. The transcripts level of ACSs and ACOs are also up-regulated under salinity. Then, salinity-induced ethylene signal is transduced mainly through the classical receptors-CTR1-EIN2-EIN3 pathway to regulate many effectors involved in plant growth and salinity response. Under proper concentration, ethylene promotes the homeostasis of $\mathrm{Na}^{+} / \mathrm{K}^{+}$, nutrients and ROS to enhance plant tolerance to salinity, with no irreversible inhibition of normal growth, while excessive ethylene will lead to harmful hyper-inhibition of plant growth. To avoid damage from extreme ethylene response, plants have evolved some negative feed-back mechanisms to alleviate ethylene response and promote seedling growth. In these mechanisms, some small proteins such as NtTCTP, NEIP2, AtSAURs, and AtARGOS are supposed to act as key modulators to coordinate plant growth and ethylene/salinity responses.

\section{NOVEL NEGATIVE FEEDBACK MECHANISMS IN ETHYLENE SIGNALING}

Generally speaking, ethylene is supposed to be a coordinator between stress response and growth. Intrinsic ethylene production and signaling is indispensable for plant rapid response to salinity and self-modification for better survival. But excessive ethylene production under continuous stress tends to largely inhibit plant growth and development, even leads to death. Therefore, tight control of ethylene homeostasis is critical for plants to survive under salinity and recover growth later. Indeed, there are multiple positive and negative feedback mechanisms for regulation of ethylene biosynthesis and signaling (reviewed in
Vandenbussche et al., 2012). In addition, some ethylene and salinity-responsive small proteins were identified as restrictors in alleviating the ethylene-inhibited growth through suppression of ethylene response and promotion of cell proliferation and/or expansion. The most typical restrictors are NEIP2 and NtTCTP, two ethylene receptor NTHK1-interacting proteins in tobacco (Cao et al., 2015; Tao et al., 2015). Both NEIP2 and NtTCTP proteins were induced by ethylene treatment. Overexpressing either of them led to reduced sensitivity to ethylene and improved vegetative growth. Further investigation revealed that NtTCTP could stabilize the ethylene receptor NTHK1 and promote cell proliferation to reduce ethylene sensitivity and alleviate ethylene-inhibition of vegetative growth (Tao et al., 2015). NTHK1 phosphorylates NEIP2 in vitro and NEIP2 can be phosphorylated in planta in response to ethylene and salt treatment. Overexpression of NEIP2 improved plant tolerance to salt and oxidative stresses (Cao et al., 2015). Recently, two studies found that ARGOS (auxin regulated gene involved in organ size) genes in Arabidopsis were induced by ethylene dose-dependently, but this induction was suppressed in ethylene-insensitive mutants. Increasing the expression of ARGOS family members reduced seedling sensitivity to ethylene (Rai et al., 2015; Shi et al., 2015). More recently, we found that AtSAUR76/77/78 could associate with subfamily II ethylene receptor ETR2 and EIN4 to reduce ethylene response and promote plant growth (Li et al., 2015b). These findings reveal novel negative feedback mechanisms of precisely desensitizing excessive ethylene response but promoting growth recovery from ethylene-inhibited growth. All these small proteins are supposed to act as brakes of ethylene signaling and accelerators of cell proliferation/expansion to coordinate normal growth and ethylene response (Figure 1). Further investigation of the roles of these factors in ethylene-mediated response to salinity and other stresses would be valuable for elucidating the overall roles of ethylene in modulation of plant growth under environmental stresses.

Considering the key role of NEIP2-type factors in constraint of ethylene signaling, gene manipulation of these factors would be an effective way to enhance plant tolerance to salinity stress. This might be achieved by using salinity-responsive promoters. A previous study showed that distinctive expression of HKT1; in the root stele of Arabidopsis reduced root-to-shoot $\mathrm{Na}^{+}$delivery, thus promoting seedling tolerance to salinity, while constitutive expressing HKT1;1 increased $\mathrm{Na}^{+}$accumulation in shoot and led to more sensitive to salinity (Moller et al., 2009). In addition, it was shown that ethylene promoted salinity tolerance largely through improving the homeostasis of $\mathrm{Na}^{+} / \mathrm{K}^{+}$(Jiang et al., 2013). These findings suggest another way to enhance salinity tolerance of plants by cell type-specific engineering of ethylene signaling.

\section{CROSS-TALKS BETWEEN RESPONSES TO SALINITY AND RESPONSES TO NUTRIENT DEFICIENCIES}

Besides ion toxicity, osmotic and oxidative stresses, high salinity also led to nutrient deficiencies (Chinnusamy et al., 2006). The most direct salinity-related nutrient is potassium $(\mathrm{K})$, which has critical roles in maintaining enzyme activities, ion homeostasis, 


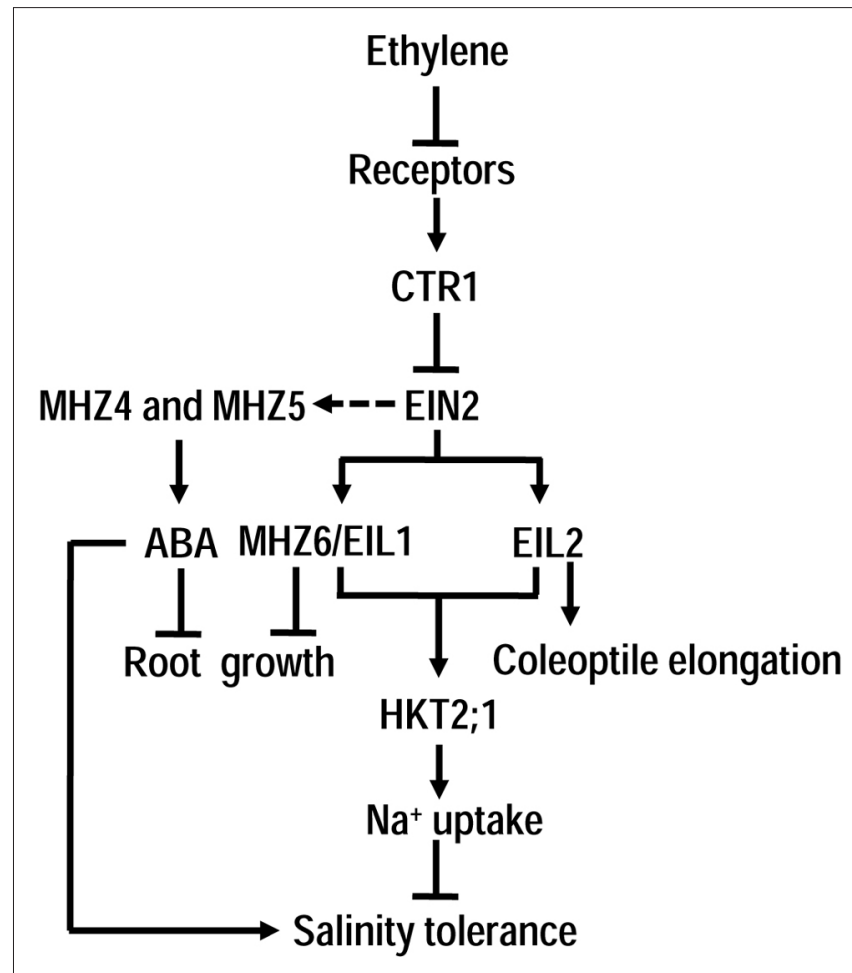

FIGURE 2 | The role of ethylene signaling in rice under salinity. Unlike in Arabidopsis, the classical CTR1-EIN2-EILs ethylene signaling in rice plays negative role in regulating plant tolerance to salinity mainly through up-regulation of OsHKT2;1, a high affinity $\mathrm{Na}^{+}$transporter with no homolog in Arabidopsis. Interestingly, EIL1 and EIL2 in rice respectively regulates ethylene-controlled roots and coleoptiles growth of etiolated seedlings. Besides, two novel ethylene signaling components MHZ4 and MHZ5 in rice may mediate the interaction between ethylene and ABA in regulation of root growth and salinity response.

internal $\mathrm{pH}$, and etc. For similar chemical feature, excessive sodium ions inhibit potassium uptake and lead to potassium deficiency. Usually, high concentration of sodium and low concentration of potassium status (high sodium/potassium ratio) is most harmful for plant cells. Similar to the vital roles of ethylene in high salinity response, ethylene also played important roles in response to potassium deficiency and acted upstream of ROS (Jung et al., 2009). One piece of evidence was that the low $\mathrm{K}^{+}$-inducible HAK5 expression was dependent on ethylene signaling (Jung et al., 2009). In addition, changes of ethylene biosynthesis and signaling often lead to alteration of sodium/potassium contents under salinity. In tobacco, ethylene receptor NTHK1-overexpressing tobacco seedlings showed higher sodium/potassium ratio than the WT (Cao et al., 2006). In fact, $\mathrm{Na}^{+} / \mathrm{K}^{+}$homeostasis is the key point for ethylene regulation of plant salinity response (Jiang et al., 2013).

In addition to potassium deficiency, ethylene also regulates plant responses to many other nutrient $(\mathrm{N}, \mathrm{P}, \mathrm{Ca}$, and $\mathrm{Fe}$ ) deficiencies through different pathways (reviewed in García et al., 2015). Among them, the most frequently studied is iron (Fe) deficiency. Previous works showed that ethylene participated in up-regulation of many important Fe-regulated genes in Strategy I plants, including ferric reductase, $\mathrm{H}^{+}$-ATPase gene and several Fe acquisition genes FIT, FRO2, and IRT1 (Lucena et al., 2006; Waters et al., 2007; García et al., 2010). Simultaneously, Fe deficiency promoted the expressions of many genes related to ethylene biosynthesis and signaling in the roots (García et al., 2010). Moreover, recent work showed that hypoxia and bicarbonate, two main factors causing Fe chlorosis in Strategy I plants, negatively regulated the expressions of $\mathrm{Fe}$ acquisition genes, probably by affecting ethylene synthesis and/or signaling (García et al., 2014). Meanwhile, salinity stress usually reduced the Fe uptake and led to Fe deficiency (Rabhi et al., 2007; Yousfi et al., 2007). Considering the positive roles of ethylene in both salinity tolerance and $\mathrm{Fe}$ acquisition, we can deduce that ethylene mediates the cross-talk between salinity and Fe deficiency responses, possibly through regulation of many genes involved in $\mathrm{Fe}$ homeostasis under salinity condition.

Another focused research field is the cross-talk between phosphate $(\mathrm{P})$ deficiency and ethylene, and a simple model has been supposed (Lei et al., 2011b). First, P starvation might induce ethylene production and enhance plant sensitivity to ethylene (He et al., 1992; Borch et al., 1999). Then enhanced ethylene production and ethylene responses would promote the development of root hair and the expression of PSI ( $P$ starvation-induced) genes (Lei et al., 2011b). These changes could directly affect $\mathrm{P}$ uptake, remobilization and redistribution, which facilitate plants to maintain $\mathrm{P}$ homeostasis under $\mathrm{P}$-deficient condition. Interestingly, ethylene alone seemed to be not enough to promote the PSI gene expression to the degree induced by $\mathrm{P}$ starvation, suggesting a cross-talk between ethylene and Pdeficiency-induced signals in controlling the PSI gene expression under low P (Lei et al., 2011b). Moreover, it was found that inhibition of ethylene biosynthesis or signaling could respectively rescued the increased primary root elongation and root hair formation caused by overexpression of the $\mathrm{P}$ transporter gene Pht1;5, providing another evidence of cross-talk between ethylene and P signaling (Nagarajan et al., 2011). Indeed, ethylene plays an integrative role in regulating both local P-deficiency responses and systemic $\mathrm{P}$ signaling pathways (reviewed in Nagarajan and Smith, 2012). Usually, high salinity led to reduced P uptake (Rai and Sharma, 2006), and phosphate-accumulating mutants siz1 and pho2 showed reduced uptake and reduced accumulation of $\mathrm{Na}^{+}$, hence enhanced plant tolerance to salinity stress (Miura et al., 2011). All these studies indicate that ethylene may mediate the cross-talk between salinity and $\mathrm{P}$ deficiency stresses.

Recently, the cross-talk between nitrate (N) deficiency and ethylene was investigated. Low nitrate treatment rapidly induced ethylene production and up-regulated the expression of EIN3/EIL1 and NRT2.1, while enhanced ethylene production and signaling down-regulated the expression of NRT2.1 and thus decreased the high-affinity nitrate uptake, indicating a negative feedback regulation of nitrate acquisition by ethylene under nitrate deficiency (Zheng et al., 2013). More recently, it was reported that cadmium and sodium stresses-induced ethylene and JA signaling converged at EIN3/EIL1 to up-regulate NRT1.8 expression but down-regulate NRT1.5 expression, thus mediated the stress-initiated nitrate allocation to roots (SINAR), which decoupled nitrate assimilation and photosynthesis, and finally 
decreased plant growth but promoted plant tolerance to stress in a nitrate reductase-dependent manner (Zhang et al., 2014).

All these findings suggest that ethylene mediates the crosstalks between plant response to salinity and responses to nutrient deficiencies. Ethylene may be a linking point in regulation of nutrient homeostasis under salinity stress to coordinate stress response and normal growth.

\section{CONCLUSION AND PERSPECTIVES}

From above studies, a general conclusion could be made that inherent ethylene production is necessary for the establishment of salt acclimation, and ethylene signaling is indispensable for plant self-adjustment in rapid response to salinity stress and better adaptation to the stress condition (summarized in Figure 1).

Different from Arabidopsis, ethylene signaling in rice seems to be more complex, so does the ethylene's role in salinity response (Figure 2). Ethylene treatment of rice seedlings increased salinity sensitivity, while 1-MCP (a blocker of ethylene perception) treatment led to enhanced tolerance to salinity. Rice MHZ7/OsEIN2, MHZ6/OsEIL1 and OsEIL2 conferred reduced tolerance to salinity (Yang et al., 2015b). MHZ6/OsEIL1 and OsEIL2 could bind to the promoter region of OsHKT2;1 (encoding a $\mathrm{Na}^{+}$transporter) and activated its expression for $\mathrm{Na}^{+}$ uptake. Ethylene-induced OsHKT2;1 expression and $\mathrm{Na}^{+}$uptake may represent a mechanism for maintaining ion homeostasis in water environment (Yang et al., 2015b). This mechanism could lead to sensitive response especially under high salinity. Different mechanisms in Arabidopsis and rice in response to salt stress may arise from the evolutionary divergence under different growing conditions or due to different plant species.

Although much progress has been made in terms of ethylene roles in salt stress responses, there are still some uncertain points left to be clarified. First, whether the functions of ACSs and ACOs on salinity response must be executed through downstream ethylene signaling? This could be solved directly through construction and analysis of double loss-of-function mutants

\section{REFERENCES}

Abeles, F. B., Morgan, P. W., and Saltveit, M. E. Jr. (1992). Ethylene in Plant Biology. San Diego, CA: Academic Press.

Achard, P., Cheng, H., De Grauwe, L., Decat, J., Schoutteten, H., Moritz, T., et al. (2006). Integration of plant responses to environmentally activated phytohormonal signals. Science 311, 91-94. doi: 10.1126/science.1 118642

Albacete, A., Martinez-Andujar, C., Ghanem, M. E., Acosta, M., Sanchez-Bravo, J., Asins, M. J., et al. (2009). Rootstock-mediated changes in xylem ionic and hormonal status are correlated with delayed leaf senescence, and increased leaf area and crop productivity in salinized tomato. Plant Cell Environ. 32, 928-938. doi: 10.1111/j.1365-3040.2009.01973.x

Ali, S., Charles, T. C., and Glick, B. R. (2014). Amelioration of high salinity stress damage by plant growth-promoting bacterial endophytes that contain ACC deaminase. Plant Physiol. Biochem. 80, 160-167. doi: 10.1016/j.plaphy.2014.04.003

Alonso, J. M., Hirayama, T., Roman, G., Nourizadeh, S., and Ecker, J. R. (1999). EIN2, a bifunctional transducer of ethylene and stress responses in Arabidopsis. Science 284, 2148-2152. doi: 10.1126/science.284.54 23.2148

An, F. Y., Zhao, Q. O., Ji, Y. S., Li, W. Y., Jiang, Z. Q., Yu, X. C., et al. (2010). Ethylene-induced stabilization of ETHYLENE INSENSITIVE3 and between ACS and EIN2 or EIN3. Second, a few studies showed that enhanced ethylene production led to salinity sensitivity (Xu et al., 2008; Li et al., 2014a), but whether this sensitivity arises from inherent weakened salinity resistance or just from ethylene-inhibited growth and promoted senescence is unclear. This could be clarified through alleviating the effects of ethylene on plant growth and development by genetic method. Third, the appropriate ethylene quantity and signaling intensity for plant response to salinity may be varied during different growing stages. Thus, precise control of ethylene production and signaling may be critical for promotion of plant salinity tolerance. This could be achieved by gene manipulation of key ethylene biosynthesis and signaling factors using specific promoters. Last, further investigation of the differences between rice and Arabidopsis on the role of ethylene in salinity response is valuable for elucidating the evolutionary divergence of ethylene in different plant species. Additionally, identification of more ethylene-response mutants and evaluation of their salt response may reveal novel components linking ethylene and salt stress. Analysis of sequence variations of known components among different cultivars may identify better alleles for salt tolerance. Uncovering these problems will largely broaden our horizon and enrich our knowledge on how plant self-adjust to coordinate external stresses and internal growing motivation for better survival. This will be helpful for precisely controlling ethylene production and signaling to enhance salinity tolerance and improve agronomic traits of crops.

\section{AUTHOR CONTRIBUTIONS}

JJT, HWC, SYC, and JSZ conceived the topic. JJT wrote the manuscript. All authors revised the manuscript.

\section{ACKNOWLEDGMENTS}

This work was supported by 973 projects (2015CB755702, 2012CB114202) and the National Natural Science Foundation of China (91317306 and 31530004).

EIN3-LIKE1 is mediated by proteasomal degradation of EIN3 binding F-Box 1 and 2 that requires EIN2 in Arabidopsis. Plant Cell 22, 2384-2401. doi: 10.1105/tpc. 110.076588

Arc, E., Sechet, J., Corbineau, F., Rajjou, L., and Marion-Poll, A. (2013). ABA crosstalk with ethylene and nitric oxide in seed dormancy and germination. Front. Plant Sci. 4:63. doi: 10.3389/fpls.2013.00063

Barnawal, D., Bharti, N., Maji, D., Chanotiya, C. S., and Kalra, A. (2014). ACC deaminase-containing Arthrobacter protophormiae induces $\mathrm{NaCl}$ stress tolerance through reduced ACC oxidase activity and ethylene production resulting in improved nodulation and mycorrhization in Pisum sativum. J. Plant Physiol. 171, 884-894. doi: 10.1016/j.jplph.2014.03.007

Beaudoin, N., Serizet, C., Gosti, F., and Giraudat, J. (2000). Interactions between abscisic acid and ethylene signaling cascades. Plant Cell 12, 1103-1115. doi: 10.1105/tpc.12.7.1103

Binder, B. M., Walker, J. M., Gagne, J. M., Emborg, T. J., Hemmann, G., Bleecker, A. B., et al. (2007). The Arabidopsis EIN3 binding F-box proteins EBF1 and EBF2 have distinct but overlapping roles in ethylene signaling. Plant Cell 19, 509-523. doi: $10.1105 /$ tpc.106.048140

Bleecker, A. B., and Kende, H. (2000). Ethylene: a gaseous signal molecule in plants. Annu. Rev. Cell Dev. Biol. 16, 1-18. doi: 10.1146/annurev.cellbio.16.1.1

Borch, K., Bouma, T. J., Lynch, J. P., and Brown, K. M. (1999). Ethylene: a regulator of root architectural responses to soil phosphorus availability. Plant Cell Environ. 22, 425-431. doi: 10.1046/j.1365-3040.1999.00405.x 
Brotman, Y., Landau, U., Cuadros-Inostroza, A., Tohge, T., Fernie, A. R., Chet, I., et al. (2013). Trichoderma-plant root colonization: escaping early plant defense responses and activation of the antioxidant machinery for saline stress tolerance. PLoS Pathog. 9:e1003221. doi: 10.1371/journal.ppat.1003221

Cao, W. H., Liu, J., He, X. J., Mu, R. L., Zhou, H. L., Chen, S. Y., et al. (2007). Modulation of ethylene responses affects plant salt-stress responses. Plant Physiol. 143, 707-719. doi: 10.1104/pp.106.094292

Cao, W. H., Liu, J., Zhou, Q. Y., Cao, Y. R., Zheng, S. F., Du, B. X., et al. (2006). Expression of tobacco ethylene receptor NTHK1 alters plant responses to salt stress. Plant Cell Environ. 29, 1210-1219. doi: 10.1111/j.1365-3040.2006.01501.x

Cao, Y. R., Chen, H. W., Li, Z. G., Tao, J. J., Ma, B., Zhang, W. K., et al. (2015). Tobacco ankyrin protein NEIP2 interacts with ethylene receptor NTHK1 and regulates plant growth and stress responses. Plant Cell Physiol. 56, 803-818. doi: $10.1093 / \mathrm{pcp} / \mathrm{pcv} 009$

Chen, D., Ma, X., Li, C., Zhang, W., Xia, G., and Wang, M. (2014). A wheat aminocyclopropane-1-carboxylate oxidase gene, TaACO1, negatively regulates salinity stress in Arabidopsis thaliana. Plant Cell Rep. 33, 1815-1827. doi: 10.1007/s00299-014-1659-7

Chen, T., Liu, J., Lei, G., Liu, Y. F., Li, Z. G., Tao, J. J., et al. (2009). Effects of tobacco ethylene receptor mutations on receptor kinase activity, plant growth and stress responses. Plant Cell Physiol. 50, 1636-1650. doi: 10.1093/pcp/pcp107

Chen, Y. F., Shakeel, S. N., Bowers, J., Zhao, X. C., Etheridge, N., and Schaller, G. E. (2007). Ligand-induced degradation of the ethylene receptor ETR2 through a proteasome-dependent pathway in Arabidopsis. J. Biol. Chem. 282, 24752-24758. doi: 10.1074/jbc.M704419200

Cheng, M. C., Liao, P. M., Kuo, W. W., and Lin, T. P. (2013). The Arabidopsis ETHYLENE RESPONSE FACTOR1 regulates abiotic stress-responsive gene expression by binding to different cis-acting elements in response to different stress signals. Plant Physiol. 162, 1566-1582. doi: 10.1104/pp.113.221911

Chinnusamy, V., Zhu, J., and Zhu, J. K. (2006). Salt stress signaling and mechanisms of plant salt tolerance. Genet. Eng. (N. Y.) 27, 141-177. doi: 10.1007/0-38725856-6_9

Christians, M. J., Gingerich, D. J., Hansen, M., Binder, B. M., Kieber, J. J., and Vierstra, R. D. (2009). The BTB ubiquitin ligases ETO1, EOL1 and EOL2 act collectively to regulate ethylene biosynthesis in Arabidopsis by controlling type-2 ACC synthase levels. Plant J. 57, 332-345. doi: 10.1111/j.1365313X.2008.03693.x

Divi, U. K., Rahman, T., and Krishna, P. (2010). Brassinosteroid-mediated stress tolerance in Arabidopsis shows interactions with abscisic acid, ethylene and salicylic acid pathways. BMC Plant Biol. 10:151. doi: 10.1186/1471-222910-151

Dong, H., Zhen, Z., Peng, J., Chang, L., Gong, Q., and Wang, N. N. (2011). Loss of ACS7 confers abiotic stress tolerance by modulating ABA sensitivity and accumulation in Arabidopsis. J. Exp. Bot. 62, 4875-4887. doi: 10.1093/jxb/ err143

Du, H., Wu, N., Cui, F., You, L., Li, X., and Xiong, L. (2014). A homolog of ETHYLENE OVERPRODUCER, OsETOL1, differentially modulates drought and submergence tolerance in rice. Plant J. 78, 834-849. doi: 10.1111/tpj.12508

Ellouzi, H., Hamed, K. B., Hernandez, I., Cela, J., Muller, M., Magne, C., et al. (2014). A comparative study of the early osmotic, ionic, redox and hormonal signaling response in leaves and roots of two halophytes and a glycophyte to salinity. Planta 240, 1299-1317. doi: 10.1007/s00425-014-2154-7

Fujimoto, S. Y., Ohta, M., Usui, A., Shinshi, H., and Ohme-Takagi, M. (2000). Arabidopsis ethylene-responsive element binding factors act as transcriptional activators or repressors of GCC box-mediated gene expression. Plant Cell 12, 393-404. doi: 10.1105/tpc.12.3.393

Gagne, J. M., Smalle, J., Gingerich, D. J., Walker, J. M., Yoo, S. D., Yanagisawa, S., et al. (2004). Arabidopsis EIN3-binding F-box 1 and 2 form ubiquitinprotein ligases that repress ethylene action and promote growth by directing EIN3 degradation. Proc. Natl. Acad. Sci. U.S.A. 101, 6803-6808. doi: 10.1073/pnas.0401698101

García, M. J., García-Mateo, M. J., Lucena, C., Romera, F. J., Rojas, C. L., Alcántara, E., et al. (2014). Hypoxia and bicarbonate could limit the expression of iron acquisition genes in Strategy I plants by affecting ethylene synthesis and signaling in different ways. Physiol. Plant. 150, 95-106. doi: 10.1111/ppl.12076

García, M. J., Lucena, C., Romera, F. J., Alcántara, E., and Pérez-Vicente, R. (2010). Ethylene and nitric oxide involvement in the up-regulation of key genes related to iron acquisition and homeostasis in Arabidopsis. J. Exp. Bot. 61, 3885-3899. doi: $10.1093 /$ jxb/erq203
García, M. J., Romera, F. J., Lucena, C., Alcántara, E., and Pérez-Vicente, R. (2015). Ethylene and the regulation of physiological and morphological responses to nutrient deficiencies. Plant Physiol. 169, 1-2. doi: 10.1104/pp.15. 00708

Ghanem, M. E., Albacete, A., Martinez-Andujar, C., Acosta, M., Romero-Aranda, R., Dodd, I. C., et al. (2008). Hormonal changes during salinity-induced leaf senescence in tomato (Solanum lycopersicum L.). J. Exp. Bot. 59, 3039-3050. doi: $10.1093 /$ jxb/ern 153

Guo, H. W., and Ecker, J. R. (2003). Plant responses to ethylene gas are mediated by SCF (EBF1/EBF2)-dependent proteolysis of EIN3 transcription factor. Cell 115, 667-677. doi: 10.1016/S0092-8674(03)00969-3

He, C. J., Morgan, P. W., and Drew, M. C. (1992). Enhanced sensitivity to ethylene in nitrogen- or phosphate-starved roots of Zea mays L. during aerenchyma formation. Plant Physiol. 98, 137-142. doi: 10.1104/pp.98.1.137

He, X. J., Mu, R. L., Cao, W. H., Zhang, Z. G., Zhang, J. S., and Chen, S. Y. (2005). AtNAC2, a transcription factor downstream of ethylene and auxin signaling pathways, is involved in salt stress response and lateral root development. Plant J. 44, 903-916. doi: 10.1111/j.1365-313X.2005.02575.x

Hsieh, E. J., Cheng, M. C., and Lin, T. P. (2013). Functional characterization of an abiotic stress-inducible transcription factor AtERF53 in Arabidopsis thaliana. Plant Mol. Biol. 82, 223-237. doi: 10.1007/s11103-013-0054-Z

Jiang, C., Belfield, E. J., Cao, Y., Smith, J. A., and Harberd, N. P. (2013). An Arabidopsis soil-salinity-tolerance mutation confers ethylene-mediated enhancement of sodium/potassium homeostasis. Plant Cell 25, 3535-3552. doi: 10.1105/tpc.113.115659

Ju, C., Yoon, G. M., Shemansky, J. M., Lin, D. Y., Ying, Z. I., Chang, J., et al. (2012). CTR1 phosphorylates the central regulator EIN2 to control ethylene hormone signaling from the ER membrane to the nucleus in Arabidopsis. Proc. Natl. Acad. Sci. U.S.A. 109, 19486-19491. doi: 10.1073/pnas.1214848109

Jung, J. Y., Shin, R., and Schachtman, D. P. (2009). Ethylene mediates response and tolerance to potassium deprivation in Arabidopsis. Plant Cell 21, 607-621. doi: 10.1105/tpc.108.063099

Kamiyoshihara, Y., Iwata, M., Fukaya, T., Tatsuki, M., and Mori, H. (2010). Turnover of LeACS2, a wound-inducible 1-aminocyclopropane-1-carboxylic acid synthase in tomato, is regulated by phosphorylation/dephosphorylation. Plant J. 64, 140-150. doi: 10.1111/j.1365-313X.2010.04316.x

Kende, H. (1993). Ethylene biosynthesis. Annu. Rev. Plant Physiol. Plant Mol. Biol. 44, 283-307. doi: 10.1146/annurev.pp.44.060193.001435

Kevany, B. M., Tieman, D. M., Taylor, M. G., Cin, V. D., and Klee, H. J. (2007). Ethylene receptor degradation controls the timing of ripening in tomato fruit. Plant J. 51, 458-467. doi: 10.1111/j.1365-313X.2007.03170.x

Kim, K., Park, S. H., Chae, J. C., Soh, B. Y., and Lee, K. J. (2014). Rapid degradation of Pseudomonas fluorescens 1-aminocyclopropane-1-carboxylic acid deaminase proteins expressed in transgenic Arabidopsis. FEMS Microbiol. Lett. 355, 193-200. doi: 10.1111/1574-6968.12456

Kukreja, S., Nandwal, A., Kumar, N., Sharma, S., Unvi, V., and Sharma, P. (2005). Plant water status, $\mathrm{H}_{2} \mathrm{O}_{2}$ scavenging enzymes, ethylene evolution and membrane integrity of Cicer arietinum roots as affected by salinity. Biol. Plant. 49, 305-308. doi: 10.1007/s10535-005-5308-4

Lei, G., Shen, M., Li, Z. G., Zhang, B., Duan, K. X., Wang, N., et al. (2011a). EIN2 regulates salt stress response and interacts with a MA3 domaincontaining protein ECIP1 in Arabidopsis. Plant Cell Environ. 34, 1678-1692. doi: 10.1111/j.1365-3040.2011.02363.x

Lei, M., Zhu, C., Liu, Y., Karthikeyan, A. S., Bressan, R. A., Raghothama, K. G., et al. (2011b). Ethylene signalling is involved in regulation of phosphate starvation-induced gene expression and production of acid phosphatases and anthocyanin in Arabidopsis. New Phytol. 189, 1084-1095. doi: 10.1111/j.14698137.2010.03555.x

Li, C. H., Wang, G., Zhao, J. L., Zhang, L. Q., Ai, L. F., Han, Y. F., et al. (2014a). The receptor-like kinase SIT1 mediates salt sensitivity by activating MAPK3/6 and regulating ethylene homeostasis in rice. Plant Cell 26, 2538-2553. doi: $10.1105 /$ tpc.114.125187

Li, J., Jia, H., and Wang, J. (2014b). cGMP and ethylene are involved in maintaining ion homeostasis under salt stress in Arabidopsis roots. Plant Cell Rep. 33, 447-459. doi: 10.1007/s00299-013-1545-8

Li, G., Meng, X., Wang, R., Mao, G., Han, L., Liu, Y., et al. (2012). Duallevel regulation of ACC synthase activity by MPK3/MPK6 cascade and its downstream WRKY transcription factor during ethylene induction in Arabidopsis. PLoS Genet. 8:e1002767. doi: 10.1371/journal.pgen.1002767 
Li, W., Ma, M., Feng, Y., Li, H., Wang, Y., Ma, Y., et al. (2015a). EIN2-directed translational regulation of ethylene signaling in Arabidopsis. Cell 163, 670-683. doi: 10.1016/j.cell.2015.09.037

Li, Z. G., Chen, H. W., Li, Q. T., Tao, J. J., Bian, X. H., Ma, B., et al. (2015b). Three SAUR proteins SAUR76, SAUR77 and SAUR78 promote plant growth in Arabidopsis. Sci. Rep. 5, 12477. doi: 10.1038/srep12477

Lin, Z., Zhong, S., and Grierson, D. (2009). Recent advances in ethylene research. J. Exp. Bot. 60, 3311-3336. doi: 10.1093/jxb/erp204

Liu, Y., and Zhang, S. (2004). Phosphorylation of 1-aminocyclopropane-1carboxylic acid synthase by MPK6, a stress responsive mitogen-activated protein kinase, induces ethylene biosynthesis in Arabidopsis. Plant Cell 16, 3386-3399. doi: 10.1105/tpc.104.026609

Lorenzo, O., Piqueras, R., Sanchez-Serrano, J. J., and Solano, R. (2003). ETHYLENE RESPONSE FACTOR1 integrates signals from ethylene and jasmonate pathways in plant defense. Plant Cell 15, 165-178. doi: 10.1105/tpc.007468

Lucena, C., Waters, B. M., Romera, F. J., García, M. J., Morales, M., Alcántara, E., et al. (2006). Ethylene could influence ferric reductase, iron transporter, and $\mathrm{H}^{+}$. ATPase gene expression by affecting FER (or FER-like) gene activity. J. Exp. Bot. 57, 4145-4154. doi: 10.1093/jxb/erl189

Ma, B., Chen, S. Y., and Zhang, J. S. (2010). Ethylene signaling in rice. Chn. Sci. Bull. 55, 2204-2210. doi: 10.1007/s11434-010-3192-2

Ma, B., He, S. J., Duan, K. X., Yin, C. C., Chen, H., Yang, C., et al. (2013). Identification of rice ethylene-response mutants and characterization of MHZ7/OsEIN2 in distinct ethylene response and yield trait regulation. Mol. Plant 6, 1830-1848. doi: 10.1093/mp/sst087

Ma, B., Yin, C. C., He, S. J., Lu, X., Zhang, W. K., Lu, T. G., et al. (2014). Ethylene-induced inhibition of root growth requires abscisic acid function in rice (Oryza sativa L.) seedlings. PLoS Genet. 10:e1004701. doi: 10.1371/journal.pgen.1004701

Ma, H., Song, L., Shu, Y., Wang, S., Niu, J., Wang, Z., et al. (2012). Comparative proteomic analysis of seedling leaves of different salt tolerant soybean genotypes. J. Proteom. 75, 1529-1546. doi: 10.1016/j.jprot.2011.11.026

Merchante, C., Brumos, J., Yun, J., Hu, Q., Spencer, K. R., Enriquez, P., et al. (2015). Gene-specific translation regulation mediated by the hormone-signaling molecule EIN2. Cell 163, 684-697. doi: 10.1016/j.cell.2015.09.036

Miura, K., Sato, A., Ohta, M., and Furukawa, J. (2011). Increased tolerance to salt stress in the phosphate-accumulating Arabidopsis mutants siz1 and pho2. Planta 234, 1191-1199. doi: 10.1007/s00425-011-1476-y

Moller, I. S., Gilliham, M., Jha, D., Mayo, G. M., Roy, S. J., Coates, J. C., et al. (2009). Shoot $\mathrm{Na}^{+}$exclusion and increased salinity tolerance engineered by cell typespecific alteration of $\mathrm{Na}^{+}$transport in Arabidopsis. Plant Cell 21, 2163-2178. doi: 10.1105/tpc.108.064568

Morgan, P. W., and Drew, M. C. (1997). Ethylene and plant responses to stress. Physiol. Plant. 100, 620-630. doi: 10.1111/j.1399-3054.1997.tb03068.x

Nagarajan, V. K., Jain, A., Poling, M. D., Lewis, A. J., Raghothama, K. G., and Smith, A. P. (2011). Arabidopsis pht1;5 mobilizes phosphate between source and sink organs and influences the interaction between phosphate homeostasis and ethylene signaling. Plant Physiol. 156, 1149-1163. doi: 10.1104/pp.111.174805

Nagarajan, V. K., and Smith, A. P. (2012). Ethylene's role in phosphate starvation signaling: more than just a root growth regulator. Plant Cell Physiol. 53, 277-286. doi: $10.1093 /$ pcp/pcr186

Peng, Z., He, S., Gong, W., Sun, J., Pan, Z., Xu, F., et al. (2014b). Comprehensive analysis of differentially expressed genes and transcriptional regulation induced by salt stress in two contrasting cotton genotypes. BMC Genomics 15:760. doi: 10.1186/1471-2164-15-760

Peng, J., Li, Z., Wen, X., Li, W., Shi, H., Yang, L., et al. (2014a). Saltinduced stabilization of EIN3/EIL1 confers salinity tolerance by deterring ROS accumulation in Arabidopsis. PLoS Genet. 10:e1004664. doi: 10.1371/journal.pgen.1004664

Potuschak, T., Lechner, E., Parmentier, Y., Yanagisawa, S., Grava, S., Koncz, C., et al. (2003). EIN3-dependent regulation of plant ethylene hormone signaling by two Arabidopsis F box proteins: EBF1 and EBF2. Cell 115, 679-689. doi: 10.1016/S0092-8674(03)00968-1

Qiao, H., Chang, K. N., Yazaki, J., and Ecker, J. R. (2009). Interplay between ethylene, ETP1/ETP2 F-box proteins, and degradation of EIN2 triggers ethylene responses in Arabidopsis. Gene Dev. 23, 512-521. doi: 10.1101/gad.1765709

Qiao, H., Shen, Z., Huang, S. S., Schmitz, R. J., Urich, M. A., Briggs, S. P., et al. (2012). Processing and subcellular trafficking of ER-tethered EIN2 control response to ethylene gas. Science 338, 390-393. doi: 10.1126/science.1225974
Qiao, Z. X., Huang, B., and Liu, J. Y. (2008). Molecular cloning and functional analysis of an ERF gene from cotton (Gossypium hirsutum). Biochim. Biophys. Acta 1779, 122-127. doi: 10.1016/j.bbagrm.2007.10.003

Rabhi, M., Barhoumi, Z., Ksouri, R., Abdelly, C., and Gharsalli, M. (2007). Interactive effects of salinity and iron deficiency in Medicago ciliaris. C. R. Biol. 330, 779-788. doi: 10.1016/j.crvi.2007.08.007

Rai, A. K., and Sharma, N. K. (2006). Phosphate metabolism in the cyanobacterium Anabaena doliolum under salt stress. Curr. Microbiol. 52, 612. doi: 10.1007/s00284-005-0043-9

Rai, M. I., Wang, X., Thibault, D. M., Kim, H. J., Bombyk, M. M., Binder, B. M., et al. (2015). The ARGOS gene family functions in a negative feedback loop to desensitize plants to ethylene. BMC Plant Biol. 15:157. doi: 10.1186/s12870-0150554-X

Shakeel, S., Gao, Z., Amir, M., Chen, Y. F., Rai, M. I., Ul Haq, N., et al. (2015). Ethylene regulates levels of ethylene-receptor/CTR1 signaling complexes in Arabidopsis thaliana. J. Biol. Chem. 290, 12415-12424. doi: 10.1074/jbc.M115.652503

Shakeel, S. N., Wang, X., Binder, B. M., and Schaller, G. E. (2013). Mechanisms of signal transduction by ethylene: overlapping and non-overlapping signalling roles in a receptor family. AoB Plants 5, plt010. doi: 10.1093/aobpla/plt010

Shen, X., Wang, Z., Song, X., Xu, J., Jiang, C., Zhao, Y., et al. (2014). Transcriptomic profiling revealed an important role of cell wall remodeling and ethylene signaling pathway during salt acclimation in Arabidopsis. Plant Mol. Biol. 86, 303-317. doi: 10.1007/s11103-014-0230-9

Shi, J., Habben, J. E., Archibald, R. L., Drummond, B. J., Chamberlin, M. A., Williams, R. W., et al. (2015). Overexpression of ARGOS genes modifies plant sensitivity to ethylene, leading to improved drought tolerance in both Arabidopsis and maize. Plant Physiol. 169, 266-282. doi: 10.1104/pp.15. 00780

Shibli, R. A., Kushad, M., Yousef, G. G., and Lila, M. A. (2007). Physiological and biochemical responses of tomato microshoots to induced salinity stress with associated ethylene accumulation. Plant Growth Regul. 51, 159-169. doi: 10.1007/s10725-006-9158-7

Solano, R., Stepanova, A., Chao, Q. M., and Ecker, J. R. (1998). Nuclear events in ethylene signaling: a transcriptional cascade mediated by ETHYLENEINSENSITIVE3 and ETHYLENE-RESPONSE-FACTOR1. Gene Dev. 12, 3703-3714. doi: 10.1101/gad.12.23.3703

Steffens, B. (2014). The role of ethylene and ROS in salinity, heavy metal, and flooding responses in rice. Front. Plant Sci. 5:685. doi: 10.3389/fpls.2014.00685

Sun, S., Yu, J. P., Chen, F., Zhao, T. J., Fang, X. H., Li, Y. Q., et al. (2008). TINY, a dehydration-responsive element (DRE)-binding protein-like transcription factor connecting the DRE- and ethylene-responsive elementmediated signaling pathways in Arabidopsis. J. Biol. Chem. 283, 6261-6271. doi: 10.1074/jbc.M706800200

Takeuchi, K., Gyohda, A., Tominaga, M., Kawakatsu, M., Hatakeyama, A., Ishii, N., et al. (2011). RSOsPR10 expression in response to environmental stresses is regulated antagonistically by jasmonate/ethylene and salicylic acid signaling pathways in rice roots. Plant Cell Physiol. 52, 1686-1696. doi: $10.1093 / \mathrm{pcp} / \mathrm{pcr} 105$

Tao, J. J., Cao, Y. R., Chen, H., Wei, W., Li, Q. T., Ma, B., et al. (2015). Tobacco TCTP interacts with ethylene receptor NTHK1 and enhances plant growth through promotion of cell proliferation. Plant Physiol. 169, 96-114. doi: 10.1104/pp. 15.00355

Tatsuki, M., and Mori, H. (2001). Phosphorylation of tomato 1-aminocyclopropane1-carboxylic acid synthase, LE-ACS2, at the C-terminal region. J. Biol. Chem. 276, 28051-28057. doi: 10.1074/jbc.M101543200

Tsuchisaka, A., and Theologis, A. (2004). Heterodimeric interactions among the 1-amino-cyclopropane-1-carboxylate synthase polypeptides encoded by the Arabidopsis gene family. Proc. Natl. Acad. Sci. U.S.A. 101, 2275-2280. doi: 10.1073/pnas.0308515101

Tsuchisaka, A., Yu, G. X., Jin, H. L., Alonso, J. M., Ecker, J. R., Zhang, X. M., et al. (2009). A combinatorial interplay among the 1-aminocyclopropane-1carboxylate isoforms regulates ethylene biosynthesis in Arabidopsis thaliana. Genetics 183, 979-1003. doi: 10.1534/genetics.109.107102

Vandenbussche, F., Vaseva, I., Vissenberg, K., and Van Der Straeten, D. (2012). Ethylene in vegetative development: a tale with a riddle. New Phytol. 194, 895-909. doi: 10.1111/j.1469-8137.2012.04100.x

Wang, K. L. C., Li, H., and Ecker, J. R. (2002). Ethylene biosynthesis and signaling networks. Plant Cell 14, S131-S151. 
Wang, N. N., Shih, M. C., and Li, N. (2005). The GUS reporter-aided analysis of the promoter activities of Arabidopsis ACC synthase genes AtACS4, AtACS5, and AtACS7 induced by hormones and stresses. J. Exp. Bot. 56, 909-920. doi: 10.1093/jxb/eri083

Wang, Y., Liu, C., Li, K., Sun, F., Hu, H., Li, X., et al. (2007). Arabidopsis EIN2 modulates stress response through abscisic acid response pathway. Plant Mol. Biol. 64, 633-644. doi: 10.1007/s11103-007-9182-7

Waters, B. M., Lucena, C., Romera, F. J., Jester, G. G., Wynn, A. N., Rojas, C. L., et al. (2007). Ethylene involvement in the regulation of the $\mathrm{H}^{+}$-ATPase CsHAl gene and of the new isolated ferric reductase CsFRO1 and iron transporter CsIRT1 genes in cucumber plants. Plant Physiol. Biochem. 45, 293-301. doi: 10.1016/j.plaphy.2007.03.011

Wen, X., Zhang, C., Ji, Y., Zhao, Q., He, W., An, F., et al. (2012). Activation of ethylene signaling is mediated by nuclear translocation of the cleaved EIN2 carboxyl terminus. Cell Res. 22, 1613-1616. doi: 10.1038/cr.2012.145

Wi, S. J., and Park, K. Y. (2002). Antisense expression of carnation cDNA encoding ACC synthase or ACC oxidase enhances polyamine content and abiotic stress tolerance in transgenic tobacco plants. Mol. Cells 13, 209-220.

Wilson, R. L., Kim, H., Bakshi, A., and Binder, B. M. (2014). The ethylene receptors ETHYLENE RESPONSE1 and ETHYLENE RESPONSE2 have contrasting roles in seed germination of Arabidopsis during salt stress. Plant Physiol. 165, 1353-1366. doi: 10.1104/pp.114.241695

Xu, J., Li, Y., Wang, Y., Liu, H., Lei, L., Yang, H., et al. (2008). Activation of MAPK kinase 9 induces ethylene and camalexin biosynthesis and enhances sensitivity to salt stress in Arabidopsis. J. Biol. Chem. 283, 26996-27006. doi: 10.1074/jbc.M801392200

Yang, C., Lu, X., Ma, B., Chen, S. Y., and Zhang, J. S. (2015a). Ethylene signaling in rice and Arabidopsis: conserved and diverged aspects. Mol. Plant 8, 495-505. doi: 10.1016/j.molp.2015.01.003

Yang, C., Ma, B., He, S. J., Xiong, Q., Duan, K. X., Yin, C. C., et al. (2015b). MHZ6/OsEIL1 and OsEIL2 regulate ethylene response of roots and coleoptiles and negatively affect salt tolerance in rice. Plant Physiol. 169, 148-165. doi: 10.1104/pp.15.00353

Yang, D. L., Yang, Y., and He, Z. (2013). Role of plant hormones and their cross-talks in rice immunity. Mol. Plant 6, 675-685. doi: 10.1093/mp/sst056

Yang, S. F., and Hoffman, N. E. (1984). Ethylene biosynthesis and its regulation in higher plants. Annu. Rev. Plant Physiol. 35, 155-189. doi: 10.1146/annurev.pp.35.060184.001103

Yin, C. C., Ma, B., Collinge, D. P., Pogson, B. J., He, S. J., Xiong, Q., et al. (2015). Ethylene responses in rice roots and coleoptiles are differentially regulated by a carotenoid isomerase-mediated abscisic acid pathway. Plant Cell 27, 1061-1081. doi: 10.1105/tpc.15.00080

Yoon, G. M., and Kieber, J. J. (2013). 1-Aminocyclopropane-1-carboxylic acid as a signalling molecule in plants. AoB Plants 5:plt017. doi: 10.1093/aobpla/plt017

Yousfi, S., Wissal, M., Mahmoudi, H., Abdelly, C., and Gharsalli, M. (2007). Effect of salt on physiological responses of barley to iron deficiency. Plant Physiol. Biochem. 45, 309-314. doi: 10.1016/j.plaphy.2007.03.013

Zhang, B., Chen, H. W., Mu, R. L., Zhang, W. K., Zhao, M. Y., Wei, W., et al. (2011a). NIMA-related kinase NEK6 affects plant growth and stress response in Arabidopsis. Plant J. 68, 830-843. doi: 10.1111/j.1365-313X.2011. 04733.x

Zhang, L. X., Li, Z. F., Quan, R. D., Li, G. J., Wang, R. G., and Huang, R. F. (2011b). An AP2 domain-containing gene, ESE1, targeted by the ethylene signaling component EIN3 is important for the salt response in Arabidopsis. Plant Physiol. 157, 854-865. doi: 10.1104/pp.111.179028

Zhang, G., Chen, M., Li, L., Xu, Z., Chen, X., Guo, J., et al. (2009). Overexpression of the soybean GmERF3 gene, an AP2/ERF type transcription factor for increased tolerances to salt, drought, and diseases in transgenic tobacco. J. Exp. Bot. 60, 3781-3796. doi: 10.1093/jxb/erp214

Zhang, G. B., Yi, H. Y., and Gong, J. M. (2014). The Arabidopsis ethylene/jasmonic acid-NRT signaling module coordinates nitrate reallocation and the trade-off between growth and environmental adaptation. Plant Cell 26, 3984-3998. doi: 10.1105/tpc.114.129296

Zhang, H., Zhang, J., Quan, R., Pan, X., Wan, L., and Huang, R. (2013). EAR motif mutation of rice OsERF3 alters the regulation of ethylene biosynthesis and drought tolerance. Planta 237, 1443-1451. doi: 10.1007/s00425-0131852-x

Zhang, J. S., Xie, C., Shen, Y. G., and Chen, S. Y. (2001). A two-component gene (NTHK1) encoding a putative ethylene receptor homolog is both developmentally- and stress-regulated in tobacco. Theor. Appl. Genet. 102, 815-824. doi: 10.1007/s001220000469

Zhao, X. C., and Schaller, G. E. (2004). Effect of salt and osmotic stress upon expression of the ethylene receptor ETR1 in Arabidopsis thaliana. FEBS Lett. 562, 189-192. doi: 10.1016/S0014-5793(04)00238-8

Zheng, D., Han, X., An, Y. I., Guo, H., Xia, X., and Yin, W. (2013). The nitrate transporter NRT2.1 functions in the ethylene response to nitrate deficiency in Arabidopsis. Plant Cell Environ. 36, 1328-1337. doi: 10.1111/pce.12062

Zhou, H. L., Cao, W. H., Cao, Y. R., Liu, J., Hao, Y. J., Zhang, J. S., et al. (2006). Roles of ethylene receptor NTHK1 domains in plant growth, stress response and protein phosphorylation. FEBS Lett. 580, 1239-1250. doi: 10.1016/j.febslet.2006.01.037

Zhu, J. K. (2007). "Plant salt stress", in eLS. Chichester: John Wiley \& Sons Ltd. doi: 10.1002/9780470015902.a0001300.pub2

Zhu, Z. Q., An, F. Y., Feng, Y., Li, P. P., Xue, L., Mu, A., et al. (2011). Derepression of ethylene-stabilized transcription factors (EIN3/EIL1) mediates jasmonate and ethylene signaling synergy in Arabidopsis. Proc. Natl. Acad. Sci. U.S.A. 108, 12539-12544. doi: 10.1073/pnas.1103959108

Conflict of Interest Statement: The authors declare that the research was conducted in the absence of any commercial or financial relationships that could be construed as a potential conflict of interest.

Copyright (c) 2015 Tao, Chen, Ma, Zhang, Chen and Zhang. This is an open-access article distributed under the terms of the Creative Commons Attribution License (CC $B Y)$. The use, distribution or reproduction in other forums is permitted, provided the original author(s) or licensor are credited and that the original publication in this journal is cited, in accordance with accepted academic practice. No use, distribution or reproduction is permitted which does not comply with these terms. 